\title{
Effect of previous strength training episode and retraining on facilitation of skeletal muscle hypertrophy and contractile properties after long-term detraining in rats
}

\author{
Sukho Lee', Kwang-Seok Hong' ${ }^{2}$, Kijeong Kim ${ }^{3, *}$ \\ 'Department of Counseling, Health, and Kinesiology, College of Education and Human Development, Texas A\&M University-San Antonio, San Antonio, TX, USA \\ 2Department of Molecular Physiology and Biological Physics, University of Virginia, Charlottesville, VA, USA \\ ${ }^{3}$ School of Exercise \& Sport Science, College of Natural Sciences, University of Ulsan, Ulsan, Korea
}

In the present study, we investigated the effects of previous strength training and retraining following long-term cessation of exercise on muscle mass and contractile properties. Female Sprague-Dawley rats $(n=24)$ aged eight weeks were randomly assigned one of the four groups: control (CON), detraining (DT), training (TR), and retraining (RT). The training regimen consisted of climbing ladder $5 \times 3$ sets, once every third day for eight weeks with weight attached to the tail. The weight carried during each training session was initially $50 \%$ of body weight and progressively increased by $10 \%$ per session. The rats in DT were detained for 20 weeks followed by eight weeks strength training. The rats in the both TR and RT groups underwent eight weeks training. DT was age matched new training group while RT was retraining group after 20 weeks of detraining. Soleus, gastrocnemius, tibialis anterior, and flexor hallucis longus (FHL) muscles were harvested in order to measure the weight, and in situ contractile properties of FHL were measured including specific twitch tension (Spt) and specific tetanic tension (Spo). TR showed significant increase in muscle mass compared to CON $(P<0.05)$. DT and RT showed significant increase in muscle mass when compared to all other groups $(P<0.05)$. There was no statistical difference in Spt and Spo among the groups. The present study showed that previous strength training facilitates retraining-induced muscle hypertrophy following long-term cessation of exercise.

Keywords: Strength training, Detraining, Retraining, Muscle mass, Contractile properties

\section{INTRODUCTION}

Decreasing in muscle force and function by muscle atrophy is the main complication of physical inactivity in modern society. The importance of training for muscle strength should be emphasized. Continuous training for muscle strength increases muscle mass and force and enhances contractile property (Klitgaard et al., 1990; Tamaki et al., 1992). The ratio of muscle mass to body weight has been used as the index of muscle hypertrophy (Roy et al., 1997; Tamaki et al., 1992). Because the training for muscle strength not only increases muscle mass but also decreases body weight, the ratio of muscle mass to body weight could not represent exact muscle hypertrophy.

Stopping exercise causes decrement in muscle function (Andersen et al., 2005). Detraining following muscle training decreased maximal muscle strength, muscular peak power, muscle mass, and nerve conduction velocity (Colliander and Tesch, 1992; Hortobágyi et al., 1993; Kraemer et al., 2002; Mujika and Padilla, 2001). It is well known that the men who experienced muscle training can increase muscle mass more rapidly when started retraining compared to the men who did not experienced muscle training (Staron et al., 1991). This phenomenon is called as "muscle memory", and exercise experience in the past is suggested to be recorded in the central nervous system (Rutherford and Jones, 1986). It was reported that hypertrophy was continuously maintained several months after detraining (Smith et al., 2003; Staron et al., 1991). Old men who re-
${ }^{*}$ Corresponding author: Kijeong Kim (D) http://orcid.org/0000-0001-9233-3096 School of Exercise \& Sport Science, College of Natural Sciences, University of Ulsan, 93 Daehak-ro, Nam-gu, Ulsan 44610, Korea

Tel: +82-52-259-2381, Fax: +82-52-259-1696, E-mail: kijeongk@ulsan.ac.kr

Received: March 6, 2016 / Accepted: April 7, 2016
This is an Open Access article distributed under the terms of the Creative Commons Attribution Non-Commercial License (http://creativecommons.org/licenses/by-nc/4.0/) which permits unrestricted non-commercial use, distribution, and reproduction in any medium, provided the original work is properly cited. 
ceived muscle training showed 9-14\% higher muscle power compared to the men who did not receive muscle training, although two years had passed after stopping exercise (Smith et al., 2003). Retraining for six weeks recovered muscle power after stopping exercise for 30 weeks was reported (Staron et al., 1991). These results suggest the possibility of "muscle memory". This theory states that the number of already made myonuclei is not be decreased after long-term stopping of exercise, and retraining potentiates muscle hypertrophy (Bruusgaard et al., 2010).

However this theory is not proved by experimental evidences. In the present study, we investigated the effects of previous strength training and retraining following long-term stopping of exercise on muscle mass and contractile properties.

\section{MATERIALS AND METHODS}

\section{Animals and treatments}

Sprague-Dawley female rats $(\mathrm{n}=24$, eight weeks in age, weighing $220 \pm 5 \mathrm{~g}$ ) were used for this experiment. The rats were divided into the 4 groups ( $n=6$ in each group): control group (CON), detraining group (DT), training group (TR), and retraining group (RT). The experimental procedures were performed in accordance with the animal care guidelines of the National Institutes of Health and the Institutional Animal Care and Use Committee of Texas A\&M University. The animals were housed under controlled temperature $\left(23^{\circ} \mathrm{C} \pm 2^{\circ} \mathrm{C}\right)$ and lighting $(08: 00$ a.m. to 20:00 p.m.) conditions with food and water available ad libitum.

The rats in the CON had no physical activity for 36 weeks, the rat in the DT had muscle training for eight weeks and then left for 20 weeks without exercise, the rats in the TR had muscle training for eight weeks, and the rats in the RT had had muscle training for eight weeks followed resting time for 20 weeks, and then had muscle training for eight weeks (Table 1).

\section{Muscle training protocol}

Stepping onto the ladder was conducted for the muscle training

Table 1. Experimental procedure

\begin{tabular}{lcccc}
\hline \multirow{2}{*}{ Group } & 1-8 weeks & 9-28 weeks & $29-36$ weeks & \\
\cline { 2 - 4 } & (8 weeks) & (20 weeks) & (8 weeks) & \\
\hline Control & - & - & - & Test \\
Detraining & ST & - & Test & - \\
Training & - & - & ST & Test \\
Retraining & ST & - & ST & Test \\
\hline
\end{tabular}

ST, stepping training. once per three days and continued for eight weeks. Length of ladder was $1 \mathrm{~m}$, interval was $2 \mathrm{~cm}$, and inclination was $85^{\circ}$ (Fig. 1). Weight was loaded at tail of each rat. Initial weight was $50 \%$ of the body weight in each rats, the weight was increased $10 \%$ of the body weight by each exercise. Stepping onto the ladder 5 times was one set and the training was composed five sets.

\section{Detraining and retraining}

The rats in the DT and RT conduced muscle training for eight weeks, and then had no exercise for 20 weeks. After rest for 20 weeks, the rats in the RT reperformed muscle training for eight weeks (Table 1).

\section{Determination of in situ contractile properties}

One day after completion of each treatment, the rats were anes-

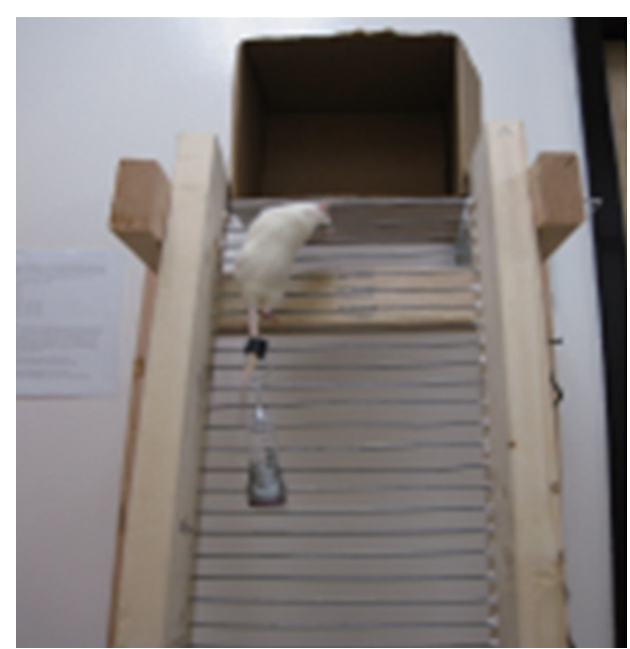

Fig. 1. Ladder climbing exercise.

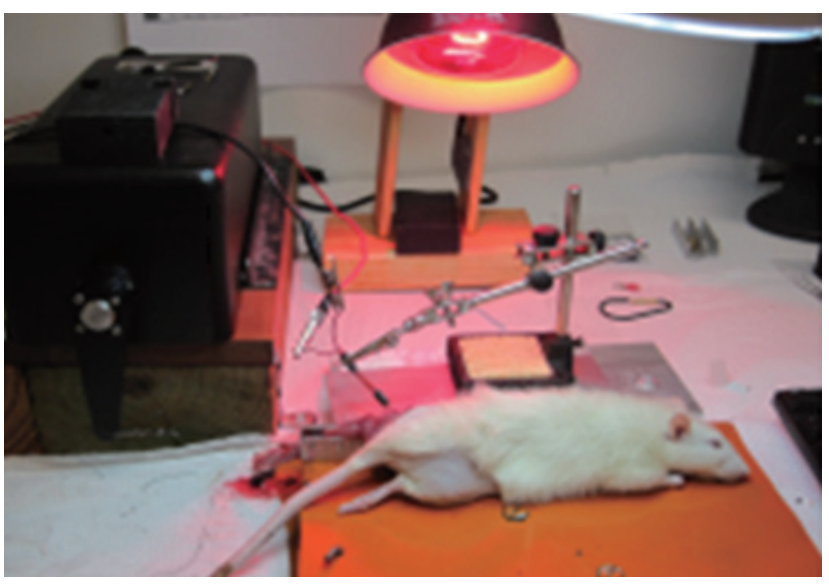

Fig. 2. In situ contractile properties measurement. 
thetized by intraperitoneal injection of pentobarbital sodium (80 $\mathrm{mg} / \mathrm{kg}$ ). After complete loss of consciousness, distal tendon of flexor hallucis longus (FHL) was connected to the dual-mode servo galvanometer (model 3005 B, Cambridge Technologies Inc., Lexington, MA, USA) (Fig. 2). And then, stimulation using Grass S88 stimulator (330 msec, 5-10 volts, $0.5 \mathrm{sec}$ ) was applied onto the sciatic nerve. Peak twitch tension, contraction time, and half-relaxation time (1/2 RT) were determined by applying electrical stimuli, $0.5 \mathrm{~Hz}$ and $7 \mathrm{~V}$. Peak tetanic tension was measured by applying electrical stimuli, $150 \mathrm{~Hz}$ and $14 \mathrm{~V}$. Determined data were analyzed using LabView ver. 3.0 (National Institutes Corp., Seoul, Korea). Resting muscle length was determined and muscle weight was measured at the end of experiment.

\section{Determination of cross sectional area}

Cross sectional area (CSA) of FHL was calculated using following equation: Calculation of CSA $\left(\mathrm{mm}^{2}\right)=$ muscle mass $(\mathrm{mg})$ $\times\left[1.06\left(\mathrm{mg} / \mathrm{mm}^{3}\right) \times \text { muscle fiber length }(\mathrm{mm})\right]^{-1}$.

Muscle fiber length was determined by nitric acid digestion technique, according to the previous described method (Brooks and Faulkner, 1988).

\section{Data analysis}

Statistical analysis was performed using one-way analysis of variance followed by Duncan post hoc test. The results are presented as the mean \pm standard error of the mean. Significance was set as $P<0.05$.

Table 2. Muscle weight in each group

\begin{tabular}{lcccc}
\hline \multirow{2}{*}{ Muscle } & \multicolumn{4}{c}{ Group } \\
\cline { 2 - 5 } & Control & Detraining & Training & Retraining \\
\hline Soleus (g) & $0.44 \pm 0.03$ & $0.42 \pm 0.12$ & $0.50 \pm 0.04^{\ddagger}$ & $0.46 \pm 0.02$ \\
Gastrocnemius (g) & $5.12 \pm 0.14$ & $5.18 \pm 0.09$ & $5.62 \pm 0.16$ & $5.66 \pm 0.21^{*}$ \\
Flexor hallucis longus (g) & $1.43 \pm 0.06$ & $1.38 \pm 0.33$ & $1.64 \pm 0.07^{*}$ & $1.91 \pm 0.10^{\dagger}$ \\
Tibialis anterior (g) & $2.03 \pm 0.07$ & $1.93 \pm 0.05$ & $2.08 \pm 0.03$ & $2.16 \pm 0.05^{\ddagger}$ \\
\hline
\end{tabular}

Values are presented as mean \pm standard error of the mean.

${ }^{*} P<0.05$, significant difference from control group. ${ }^{\dagger} P<0.05$, significant difference from training group. ${ }^{\ddagger} P<0.05$, significant difference from detraining group.

Table 3. Cross sectional area of flexor hallucis longus

\begin{tabular}{lcccc}
\hline \multirow{2}{*}{ Muscle } & \multicolumn{4}{c}{ Group } \\
\cline { 2 - 5 } & Control & Detraining & Training & Retraining \\
\hline Flexor hallucis longus $\left(\mathrm{mm}^{2}\right)$ & $0.52 \pm 0.03$ & $0.52 \pm 0.01$ & $0.52 \pm 0.02$ & $0.65 \pm 0.03^{*}$
\end{tabular}

Values are presented as mean \pm standard error of the mean.

${ }^{*} P<0.05$, significant difference from control group.

\section{RESULTS}

\section{Muscle weight change}

Table 2 shows the change in muscle weight. In the soleus, the heaviest weigh was observed in TR $(0.50 \pm 0.04 \mathrm{~g})$. In the gastrocnemius, the heaviest weigh was observed in RT $(5.66 \pm 0.21 \mathrm{~g})$. In the FHL, the weight in TR was heavier than CON, and the heaviest weight was observed in RT $(1.91 \pm 0.10 \mathrm{~g})$. In the tibialis anterior (TA), the heaviest weight was observed in RT $(2.16 \pm 0.05 \mathrm{~g})$.

\section{CSA change}

Table 3 shows CSA change in FHL. CSA in FHL was higher in RT $\left(0.65 \pm 0.03 \mathrm{~mm}^{2}\right)$.

\section{Contractile properties change}

Table 4 shows the contractile properties in FHL. Peak twitch tension contraction time (PtCT) was significantly changed in RT ( $44.13 \pm 1.39 \mathrm{msec})$ compared to DT ( $49.33 \pm 2.27 \mathrm{msec})$.

\section{DISCUSSION}

Skeletal muscle is a tissue that has high plasticity which is affected by exercise, nutrition, and mechanical stimuli. In the present results, Ladder climbing exercise increase the weight in soleus and FHL and the cross sectional are in FHL. These results are similar to the study of Lee et al. (2004).

After detraining for 20 weeks, the weight of soleus, FHL, and TA showed decreasing tendency although there was no statistical significance, similar to the results of Andersen et al. (2005). The

Table 4. Flexor hallucis longus contractile properties

\begin{tabular}{lcccc}
\hline \multirow{2}{*}{$\begin{array}{c}\text { Contractile } \\
\text { property }\end{array}$} & \multicolumn{4}{c}{ Group } \\
\cline { 2 - 5 } & Control & Detraining & Training & Retraining \\
\hline Mlo (cm) & $3.68 \pm 0.08$ & $3.71 \pm 0.09$ & $3.70 \pm 0.06$ & $3.50 \pm 0.04$ \\
Pt (N) & $2.69 \pm 0.35$ & $2.81 \pm 0.22$ & $2.15 \pm 0.29$ & $2.47 \pm 0.26$ \\
PtCT (msec) & $44.88 \pm 1.36$ & $49.33 \pm 2.27$ & $46.17 \pm 0.74$ & $44.13 \pm 1.39^{*}$ \\
PtHRT (msec) & $33.75 \pm 3.56$ & $25.83 \pm 1.37$ & $30.13 \pm 1.28$ & $29.71 \pm 3.30$ \\
Po (N) & $8.91 \pm 1.22$ & $10.62 \pm 0.75$ & $9.15 \pm 1.30$ & $8.27 \pm 0.73$ \\
PoCT (msec) & $267.42 \pm 15.21$ & $230.71 \pm 19.91$ & $260.08 \pm 18.09$ & $214.54 \pm 38.57$ \\
Spt (N/cm²) & $5.16 \pm 0.66$ & $5.44 \pm 0.49$ & $4.18 \pm 0.61$ & $3.84 \pm 0.46$ \\
Spo (N/cm²) & $17.08 \pm 2.37$ & $20.51 \pm 1.70$ & $17.84 \pm 2.79$ & $12.84 \pm 1.25$ \\
\hline
\end{tabular}

Values are presented as mean \pm standard error of the mean.

Mlo, resting muscle length; Pt, peak twitch tension; PtCT, peak twitch tension contraction time; PtHRT, peak twitch tension half relaxation time; Po, peak tetanic tension; PoCT, peak tetanic tension contraction time; Spt, specific peak twitch tension; Spo, specific peak tetanic tension.

${ }^{*} P<0.05$, significant difference from detraining group. 
weight of FHL was most potently increased by ladder climbing exercise, suggesting muscle memory hypothesis. Staron et al. (1991) suggested that muscle hypertrophy is rapidly recovered by retraining following long-term cessation of exercise in elite athletics. Bruusgaard et al. (2010) also explained that this event is the result of motor learning of the central nervous system.

In the present results, there was no statistical significance in the contractile properties of FHL, except PtCT. There was no statistical difference in specific twitch tension and specific tetanic tension among the groups. These results can be ascribed to the short-term duration of retraining.

The present study showed that previous strength training facilitates retraining-induced muscle hypertrophy following longterm cessation of exercise. In addition, it was shown that ladder climbing exercise is one of the effective methods for muscle training.

\section{CONFLICT OF INTEREST}

No potential conflict of interest relevant to this article was reported.

\section{ACKNOWLEDGMENTS}

This work was supported by the National Research Foundation of Korea Grant funded by the Korean Government (NRF-2011356-G00013).

\section{REFERENCES}

Andersen LL, Andersen JL, Magnusson SP, Suetta C, Madsen JL, Christensen LR, Aagaard P. Changes in the human muscle force-velocity relationship in response to resistance training and subsequent detraining. J Appl Physiol (1985) 2005;99:87-94.

Brooks SV, Faulkner JA. Contractile properties of skeletal muscles from young, adult and aged mice. J Physiol 1988;404:71-82.

Bruusgaard JC, Johansen IB, Egner IM, Rana ZA, Gundersen K. Myonuclei acquired by overload exercise precede hypertrophy and are not lost on detraining. Proc Natl Acad Sci U S A 2010;107:15111-15116.

Colliander EB, Tesch PA. Effects of detraining following short term resistance training on eccentric and concentric muscle strength. Acta Physiol Scand 1992;144:23-29.

Hortobágyi T, Houmard JA, Stevenson JR, Fraser DD, Johns RA, Israel RG. The effects of detraining on power athletes. Med Sci Sports Exerc 1993;25:929-935.

Klitgaard H, Zhou M, Richter EA. Myosin heavy chain composition of single fibres from $\mathrm{m}$. biceps brachii of male body builders. Acta Physiol Scand 1990;140:175-180.

Kraemer WJ, Koziris LP, Ratamess NA, Hakkinen K, Triplett-Mcbride NT, Fry AC, Gordon SE, Volek JS, French DN, Rubin MR, Gomez AL, Sharman MJ, Michael Lynch J, Izquierdo M, Newton RU, Fleck SJ. Detraining produces minimal changes in physical performance and hormonal variables in recreationally strength-trained men. J Strength Cond Res 2002;16:373-382.

Lee S, Barton ER, Sweeney HL, Farrar RP. Viral expression of insulin-like growth factor-I enhances muscle hypertrophy in resistance-trained rats. J Appl Physiol (1985) 2004;96:1097-1104.

Mujika I, Padilla S. Muscular characteristics of detraining in humans. Med Sci Sports Exerc 2001;33:1297-1303.

Roy RR, Wilson R, Edgerton VR. Architectural and mechanical properties of the rat adductor longus: response to weight-lifting training. Anat Rec 1997;247:170-178.

Rutherford OM, Jones DA. The role of learning and coordination in strength training. Eur J Appl Physiol Occup Physiol 1986;55:100-105.

Smith K, Winegard K, Hicks AL, McCartney N. Two years of resistance training in older men and women: the effects of three years of detraining on the retention of dynamic strength. Can J Appl Physiol 2003; 28:462-474.

Staron RS, Leonardi MJ, Karapondo DL, Malicky ES, Falkel JE, Hagerman FC, Hikida RS. Strength and skeletal muscle adaptations in heavy-resistance-trained women after detraining and retraining. J Appl Physiol (1985) 1991;70:631-640.

Tamaki T, Uchiyama S, Nakano S. A weight-lifting exercise model for inducing hypertrophy in the hindlimb muscles of rats. Med Sci Sports Exerc 1992;24:881-886. 